\title{
A rapid synthesis and antibacterial property of selenium nanoparticles using egg white lysozyme as a stabilizing agent
}

\author{
Sakthivel Muthu ${ }^{1,2}$ (Dictor Raju ${ }^{1} \cdot$ Venkatesh Babu Gopal ${ }^{1} \cdot$ Amsaveni Gunasekaran $^{2} \cdot$ Karthik S. Narayan $^{1}$. \\ Sathuvan Malairaj ${ }^{1} \cdot$ Mythileeswari Lakshmikanthan $^{1} \cdot$ Nallusamy Duraisamy $^{2} \cdot$ Kathiravan Krishnan $^{2}$. \\ Palani Perumal ${ }^{1}$
}

Received: 7 March 2019 / Accepted: 16 October 2019 / Published online: 4 November 2019

(c) Springer Nature Switzerland AG 2019

\begin{abstract}
A simple method for the rapid synthesis of selenium nanoparticles (SeNPs) by the reduction of selenium dioxide using an aqueous egg white lysozyme solution (stabilizing agent) and ascorbic acid solution (reducing agent) has been described. The formation of SeNPs is assured by characterization with UV-Vis, FT-IR, XRD and morphological characters that were observed using TEM analyses. The absorbance of the SeNPs is found at $250 \mathrm{~nm}$. The TEM images show that the SeNPs are uniform and in spherical shape of size $40-60 \mathrm{~nm}$. The crystalline nature of SeNPs is assured by XRD analysis. The antibacterial property of synthesized SeNPs was tested against the pathogenic bacteria, i.e., Bacillus subtilis, Bacillus cereus, Escherichia coli, Staphylococcus pneumoniae, Proteus mirabilis and Klebsiella pneumoniae. SeNPs showed more antibacterial activity against $B$. subtilis $(19 \mathrm{~mm})$ and Streptococcus pneumoniae $(15 \mathrm{~mm})$ as compared with commercially available antibiotics such as streptomycin and erythromycin. The SeNPs synthesized via this process has proficient antimicrobial activity against pathogenic bacteria. SeNPs could play a significant role in pharmaceutical industries for the development of efficient antibiotic agents.
\end{abstract}

\section{Graphical abstract}

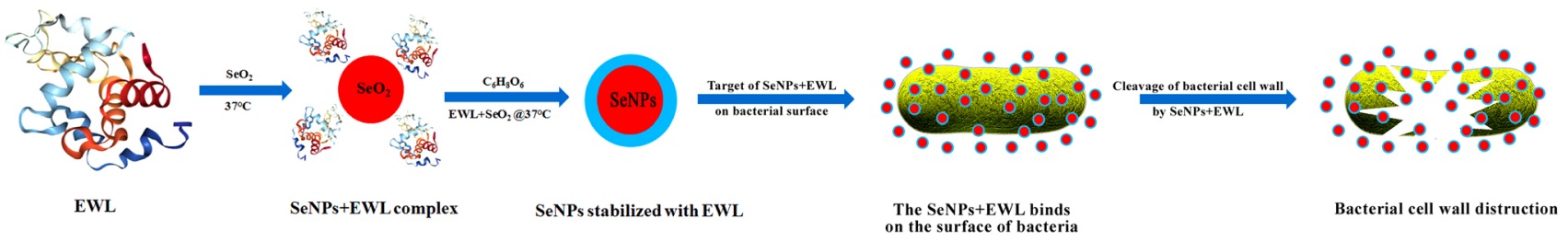

Keywords Selenium nanoparticles $\cdot$ Egg white lysozyme $\cdot$ Antibacterial activity $\cdot$ Pathogenic bacteria $\cdot$ TEM analyses

\section{Introduction}

Nanotechnology is a futuristic and emerging discipline in science concerning the creation or manipulation of particles and materials in nanoscale sizes [1-3]. The most significant characteristic of nanoparticles is that the chemical, physical and biological properties of nanoparticles are quite different from the properties of the same materials on a larger scale $[4,5]$. These materials are obtained from the structured arrangement of groups of atoms

$\bowtie$ Sakthivel Muthu, saktthivel@gmail.com; $\bowtie$ Palani Perumal, palanii7@yahoo.com | ${ }^{1}$ Centre for Advanced Studies in Botany, University of Madras, Guindy Campus, Chennai, Tamilnadu 600025, India. ${ }^{2}$ Department of Biotechnology, University of Madras, Guindy Campus, Chennai, Tamilnadu 600025, India. 
and molecules or by minimizing macroscopic materials into a nanometer scale $[6,7]$. In the present years, various novel nanoparticles have received much attention due to their great potential in biomedical sciences $[8,9]$, engineering $[10,11]$, agriculture $[12,13]$ and food safety $[14,15]$. Among them, selenium nanoparticles (SeNPs) are emerging as promising nanoparticles that can potentially be used for a wide range of applications $[16,17]$. This element can be considered as an essential trace element micronutrient for living creatures at low concentrations, but it becomes toxic and harmful at higher doses. Normal selenium levels in adults are around $81 \mathrm{mg}$, and the dietary requirement is $\sim 55 \mathrm{mg}$ per day, with an upper limit of $\sim 400 \mathrm{mg}[18,19]$. SeNPs have been sold on the market as a food additive in a tea product that claims to possess several health benefits $[17,20]$. Some studies have shown that SeNPs have unique antibacterial activities [21, 22] and antifungal activities $[23,24]$. SeNPs can be used for food safety applications which includes as antibacterial nanocoatings $[25,26]$, in food packaging $[27,28]$ and in functional foods $[29,30]$.

Recently, many efforts have been made in the fabrication of bioactive and biocompatible nanoparticles for a variety of applications [31, 32]. For example, DNA [33, 34], peptides [35, 36] and proteins [33] have been bioconjugated to nanoparticles with the use of the intermediate protecting agents of the nanoparticles or the linking agents [37]. Nowadays, research on direct conjugation of biocompatible agents and biomolecules to nanoparticles is accomplishable [38]. For example, SeNPs capped with biocompatible agents, such as lipid bilayers $[39,40]$ and dendrimers [41], have been prepared with water solubility and potential biocompatibility. Biomolecules, such as amino acid, have also been used as protective agents for the formation of SeNPs. For example, L-cysteine-capped SeNPs were used for biomedical applications that have been reported by Prasanth et al. [42].

Lysozyme is a commercially valuable small enzyme with an antibacterial function. It kills bacteria by breaking down the cell walls of bacteria and makes the bacteria burst under their internal pressure [43]. Furthermore, evidence has recently shown that the lysozyme is also an active agent for killing human immunodeficiency virus (HIV) in vitro [44]. Lysozyme is readily available, and its structure and properties are well known. The previous reports showed that the lysozyme-coated silver nanoparticles for differentiating bacterial strains based on antibacterial activity [45]. Lysozyme is present in nature as part of the innate immune system in higher organisms and primarily acts against bacteria through enzymatic hydrolysis of the peptidoglycan layer that surrounds the cell membrane [46]. To further explore the mechanisms of nanoparticle formation and expand the repertoire of antimicrobial materials, we investigated methods to integrate lysozyme with SeNPs to form multifunctional antimicrobial agents. Using lysozyme as the catalyst, preparations of selenium nanoparticles were synthesized, and the physical and chemical properties were assessed to characterize the functionality of these hybrid bioinorganic composites. The material was also incubated with a variety of bacterial strains to determine whether the antimicrobial properties of lysozyme, as well as the biocidal effects of selenium, were investigated to develop new bio-nanocomposites.

The synthesized selenium nanoparticles were characterized by UV-Vis, FT-IR, XRD and TEM analyses. This study reports for the first time, the preparation and synthesis mechanism of SeNPs using ascorbic acid and egg white lysozyme (EWL) as reducing and stabilizing agent, respectively. This work has been carried out to produce a costeffective synthesis of spherical SeNPs at an appropriate temperature with shorter reaction times. Further, we have described in detail the formation of SeNPs, which were stabilized with EWL molecules. Moreover, the synthesized SeNPs was also investigated for its antibacterial activity against different pathogenic bacteria. Our result signifies that the synthesized SeNPs, along with EWL, are suitable for the formulation of new types of bactericidal agents.

\section{Materials and methods}

\subsection{Materials}

The purified egg white lysozyme was obtained from Sigma-Aldrich (St. Louis, USA). Selenium dioxide $\left(\mathrm{SeO}_{2}\right)$ was purchased from Bio-Rad (California, USA). Ascorbic acid was procured from Qualigens Fine Chemicals Co. Ltd (Mumbai, India). Bacteriological media components were purchased from Hi-Media (Mumbai, India). All the other chemicals utilized in this study were of analytical grade procured from Sisco Research Laboratories (Mumbai, India).

\subsection{Preparation and synthesize of SeNPs stabilized with EWL}

A stock solution of $0.01 \% \mathrm{EWL}$ and $0.04 \mathrm{M} \mathrm{SeO}_{2}$ was subsequently prepared in double-distilled water. $0.04 \mathrm{M}$ of the solution of ascorbic acid was added to prepare $\mathrm{SeO}_{2}$ solution. Color change from honey yellow to dark red was observed, indicating the presence of SeNPs. In the following, the synthesis of SeNPs was carried out according to the method described by Xia [47]. 


\subsection{Characterization of SeNPs stabilized with EWL}

The synthesized SeNPs stabilized with EWL were characterized by UV-Vis, FT-IR, TEM and XRD analysis.

\subsubsection{UV-visible spectral analysis}

Hitachi 2900 absorption spectrophotometer was used for the absorption spectral studies. The nanosolution was filtered through a 0.2 micron sterilized filter to set apart impurities, if any, before the UV-visible spectral studies.

\subsubsection{FT-IR spectral analysis}

FT-IR spectroscopy was performed to study the chemical interactions in SeNPs formulations. A small quantity of SeNPs was mixed with $\mathrm{KBr}$, and then, the mixture was pelleted out with a pressure of $150 \mathrm{~kg} \mathrm{~cm}^{-2}$. The pellet was studied using EQUINOX (Bruker) FT-IR spectrophotometer in the range of 4000 to $450 \mathrm{~cm}^{-1}$.

\subsubsection{X-ray diffraction analysis}

The crystallographic phase of the SeNPs stabilized with EWL was determined on Philips X-ray diffractometer over the $2 \theta$ range from 10 to $70^{\circ}$ at a rate of $4 \% \mathrm{~min}$ using $\mathrm{Cu}$ $\mathrm{K}_{\alpha}$ radiation $(\lambda=1.54060 \AA$ ̊). Philips PW 1830 (USA) X-ray generator was operated at a voltage of $40 \mathrm{kV}$.

\subsubsection{TEM analysis}

The shape and size of SeNPs stabilized with EWL were characterized by TEM (JEOL, JEM-2100, Japan). The samples were prepared by placing $3.0 \mu \mathrm{l}$ of the nanosolution filtrate on the carbon-coated copper grid as a thin film.

\subsection{Antibacterial study of SeNPs stabilized with EWL}

The antibacterial activity of SeNPs stabilized with EWL was studied by the agar diffusion method. Different pathogenic bacterial strains such as Bacillus subtilis, Streptococcus pneumoniae, Bacillus cereus, Escherichia coli, Proteus mirabilis and Klebsiella pneumoniae were used for this analysis. The primary cultures of the organisms were subcultured in Luria-Bertani (LB) broth at $35^{\circ} \mathrm{C}$ and kept on a rotary shaker at $200 \mathrm{rpm}$ for $24 \mathrm{~h}$. The Mueller-Hinton agar (MHA) plates were swabbed with 24-h-old bacterial cells to produce a lawn culture $\left(1 \times 10^{6} \mathrm{cfu} \mathrm{ml}^{-1}\right)$. Paper disks of $6 \mathrm{~mm}$ (Hi-Media, India) were impregnated with SeNPs $\left(10.0 \mu \mathrm{g} \mathrm{ml}^{-1}\right)$. The disks were gently pressed to get better contact with MHA. The plates were incubated upside down for $24 \mathrm{~h}$ at $37^{\circ} \mathrm{C}$. After incubation, the different levels of the zones of inhibitions were measured. After incubation, the susceptibility of the test organisms was calculated by measuring the diameter of the zone of inhibition.

\subsection{Statistical analysis}

Statistical analyses were carried out using GraphPad Prism 6.0 software (San Diego, CA, USA). Data values were presented as mean $\pm S E M$. Differences between two groups were assessed by using Student's $t$ test. Statistical significance is reported as highly significant using ${ }^{* *}(p<0.002)$.

\section{Results}

In the present study, we have reported a rapid synthesis of SeNPs within $2 \mathrm{~h}$. The preparation method of SeNPs using EWL as both stabilizing and mild reducing agents in water is quite simple. The ascorbic acid was added dropwise to the $\mathrm{SeO}_{2}$ in the presence of EWL to synthesis SeNPs within a shorter duration. The aqueous selenium turned from honey yellow to dark red color within $2 \mathrm{~h}$ (Fig. 1B).

\subsection{Synthesis of SeNPs stabilized with EWL}

Uniform shaped SeNPs stabilized with EWL were synthesized via reduction of selenium dioxide in the presence of ascorbic acid as a reducing agent and EWL as a stabilizing agent. The color intensity increased as the incubation time increased. The change of color was observed at two different time intervals (i.e., $1 \mathrm{~h}$ (Fig. 1Bb) and $2 \mathrm{~h}$ (Fig. 1BC)). The maximum color intensity was seen in the solution incubated for $2 \mathrm{~h}$ (Fig. 1BC).

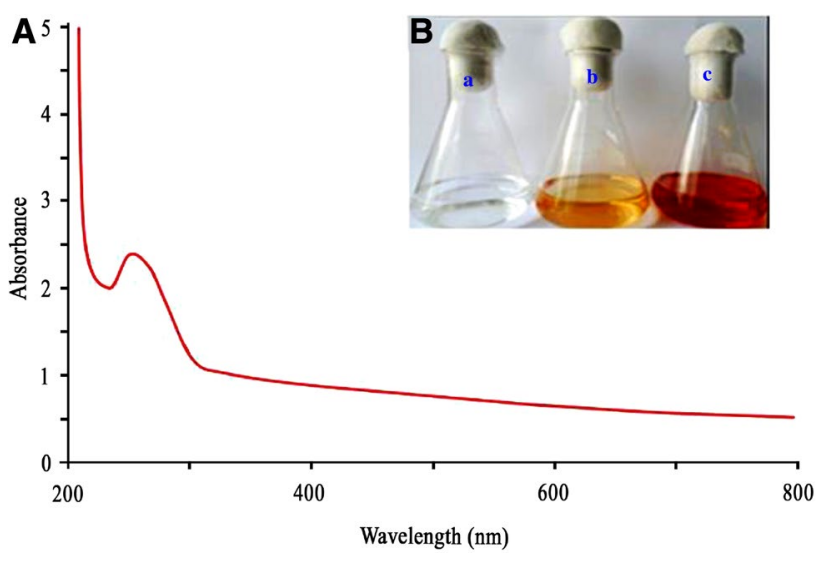

Fig. 1 A UV-Vis absorption spectrum of SeNPs stabilized EWL. B Visual observation of the color change of SeNPs stabilized with EWL at different time intervals ( $\mathrm{a}-$ Control; $\mathrm{b}-1 ; \mathrm{c}-2 \mathrm{~h}$ ) 


\subsection{Characterization of SeNPs stabilized with EWL}

\subsubsection{UV-vis spectral analysis}

The formation of SeNPs stabilized with EWL via the reduction of selenium dioxide was monitored in the UV-visible spectrophotometer. A strong characteristic absorption peak at $250 \mathrm{~nm}$ was indicating the presence of the SeNPs (Fig. 1A).

\subsubsection{FT-IR spectral analysis}

The FT-IR spectrum of SeNPs showed bands at $3533 \mathrm{~cm}^{-1}$ and $3414 \mathrm{~cm}^{-1}$, which are characteristic of hydroxyl groups. The bands at $1312 \mathrm{~cm}^{-1}$ and $1269 \mathrm{~cm}^{-1}$ correspond to the aromatic $\mathrm{C}-\mathrm{N}$ stretching vibrations. The absorbance band at $1665 \mathrm{~cm}^{-1}$ is characteristic of $\mathrm{C}=\mathrm{C}$ stretching (Fig. 2; purple line). However, the FT-IR spectrum of SeNPs stabilized with EWL showed bands at $3301 \mathrm{~cm}^{-1}$ and $2961 \mathrm{~cm}^{-1}$ that were characteristic of hydroxyl groups. The bands at $1308 \mathrm{~cm}^{-1}$ and $1239 \mathrm{~cm}^{-1}$ correspond to the aromatic primary amine $\mathrm{C}-\mathrm{N}$ stretching vibration, while the bands at $1171 \mathrm{~cm}^{-1}$ and $1105 \mathrm{~cm}^{-1}$ were characteristic of tertiary and primary $\mathrm{C}-\mathrm{N}$ stretching vibrations. The absorbance band at $1648 \mathrm{~cm}^{-1}$ was characteristic of $\mathrm{C}=\mathrm{C}$ stretching. The absorbance bands at $668,743,897$ and $932 \mathrm{~cm}^{-1}$ were due to aromatic skeleton. The peak at $1536 \mathrm{~cm}^{-1}$ was due to aromatic $\mathrm{C}-\mathrm{H}$ stretching vibration. These data suggest that the stabilization of the nanoparticles was probably due to the presence of aromatic and hydroxyl groups of EWL (Fig. 2; blue line).

\subsubsection{XRD analysis}

The crystallite structure of synthesized SeNPs was characterized by XRD and also estimated its crystallite size based on the elastic scattering of the X-rays. XRD analysis showed three distinct diffraction peaks at $35.5^{\circ}, 30.0^{\circ}, 27.1^{\circ} 29.7^{\circ}$ and $27.8^{\circ}$, indexed to $2451,725,591,477$ and 281 , respectively, corresponding to the planes of cubic face-centered SeNPs. The lattice constant calculated for this pattern was a $4.086 \mathrm{~A}^{0}$, which is in agreement with the standard lattice parameter of SeNPs confirming the presence of crystallite structure (standards file No.NP-194A). Scherr's formula determined the average grain size of the SeNPs formed in the detection process, $d=\left(0.9 \lambda^{*} 180^{\circ}\right) / \beta \cos \theta \pi$, and was estimated to be $54 \mathrm{~nm}$ (Fig. 3).

\subsubsection{TEM analysis}

The size and morphology of the SeNPs stabilized with EWL were analyzed by TEM. The TEM micrograph shows

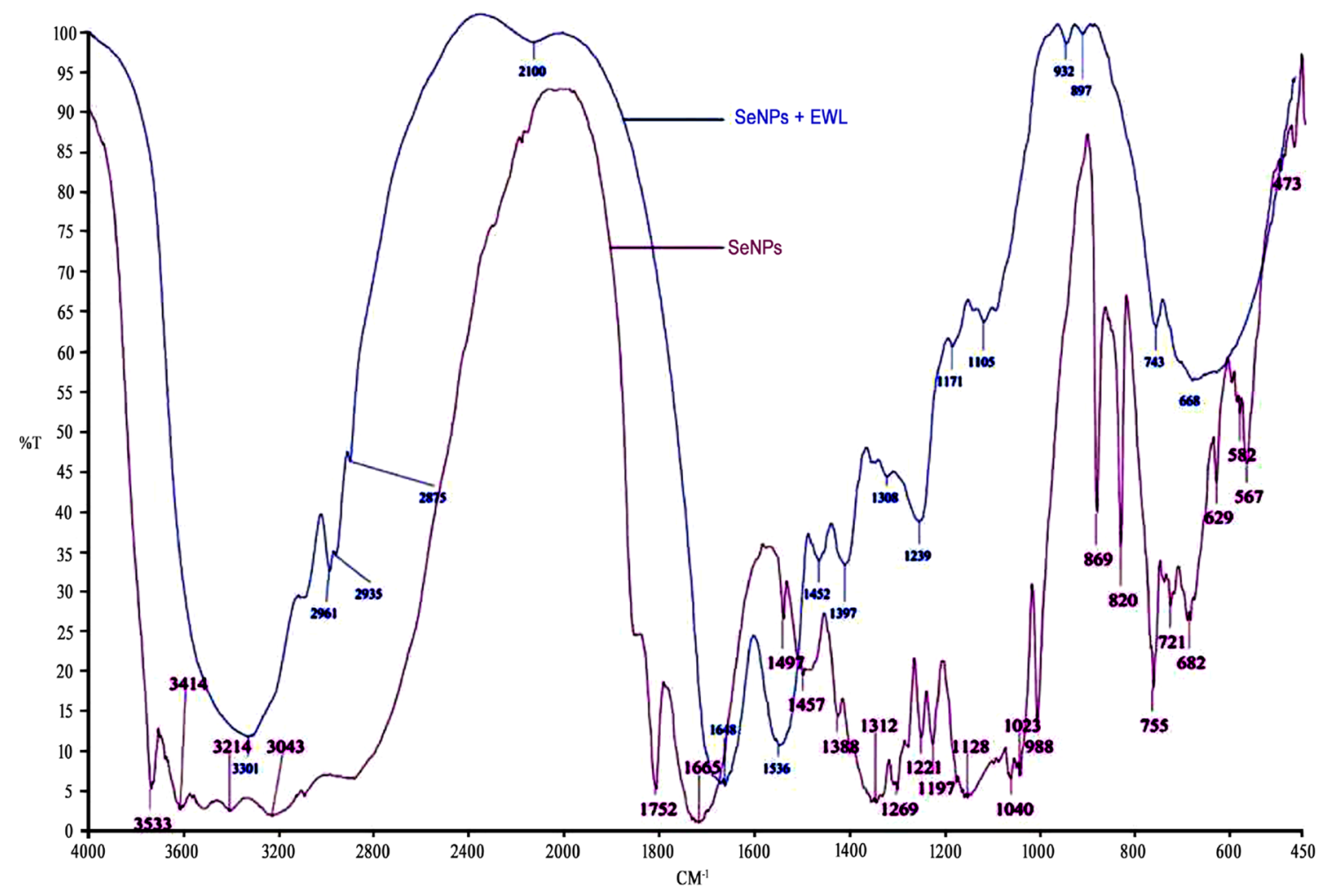

Fig. 2 FT-IR spectral analyses of SeNPs (Purple color) and SeNPs stabilized with EWL (Blue color) 


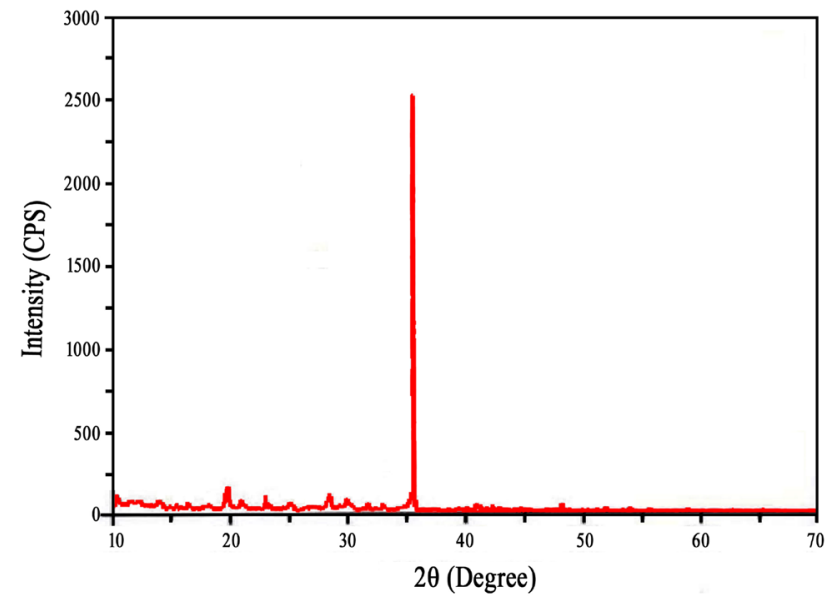

Fig. 3 X-ray different patterns of the SeNPs stabilized with EWL

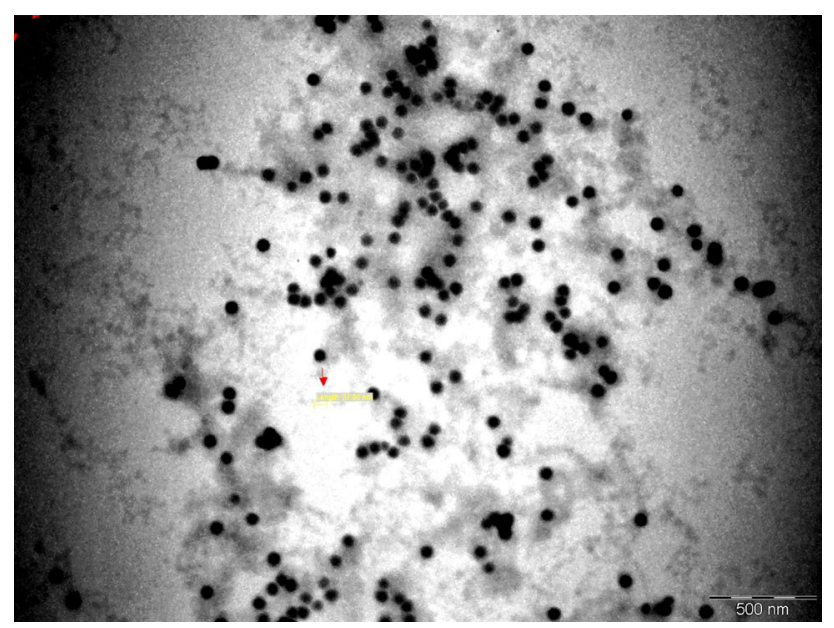

Fig. 4 TEM image of SeNPs stabilized EWL

well-dispersed spherical particles, with a diameter range of $40-60 \mathrm{~nm}$ (Fig. 4).

\subsubsection{Effect of stability of SeNPs stabilized with EWL visualized under TEM analysis}

To determine long-term stability versus aggregation of the synthesized SeNPs stabilized with EWL, the samples were preserved in storage vials at ambient temperature in the absence of light. Further, the UV-Vis spectra were recorded periodically for 12 months, and the SeNPs stabilized with EWL aggregation were visualized under a TEM image (Fig. 5). It was found that the particle size remained constant (Fig. 6).

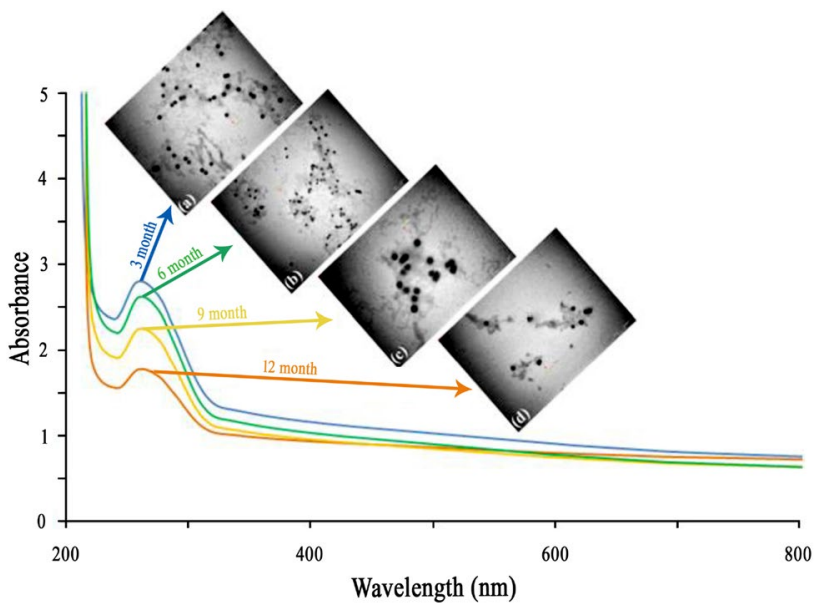

Fig. 5 Long term stability of SeNPs stabilized EWL visualized under TEM analyses

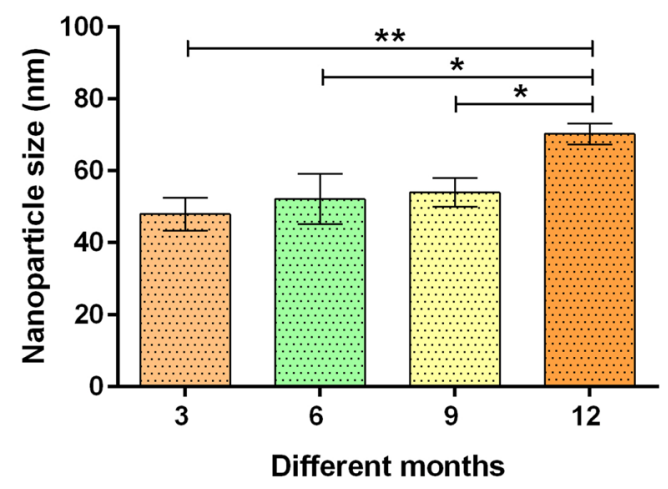

Fig. 6 Stability assessment of EWL stabilized with SeNPs were optimized with different months

\subsection{Antimicrobial studies SeNPs stabilized with EWL}

\subsubsection{MIC and antibacterial activity under TEM analysis}

The SeNPs stabilized with EWL were used to evaluate its antibacterial potential agent bacteria. $10.0 \mathrm{\mu g} \mathrm{ml}^{-1}$ of SeNPs stabilized with EWL was efficient to curb the growth of B. subtilis, S. pneumoniae, B. cereus, E. coli, P. mirabilis and K. pneumoniae. The highest zone of inhibition $(19 \mathrm{~mm})$ was recorded against $B$. subtilis followed by $E$. coli $(15 \mathrm{~mm}), B$. cereus $(14 \mathrm{~mm})$, S. pneumoniae $(13 \mathrm{~mm})$ and P. mirabilis $(11 \mathrm{~mm})$. Though SeNPs has the ability to inhibit the growth of both gram-positive and gram-negative bacteria, the heightened response was observed against grampositive bacteria. The SeNPs stabilized with EWL has not inhibited the growth of $K$. pneumoniae (Table 1), and the reason why SeNPs stabilized with EWL failed to inhibit the bacterium remains to be investigated. TEM image reveals 
Table 1 Antibacterial activity of SeNPs stabilized with EWL against different pathogenic bacteria

\begin{tabular}{llll}
\hline Microorganisms & \multicolumn{2}{l}{ Zone of inhibition $(\mathrm{mm})$} \\
\cline { 2 - 4 } & Streptomycin & Erythromycin & SeNPs + EWL \\
\hline B. subtilis & $24 \pm 0.41$ & - & $19 \pm 0.77$ \\
S. pneumoniae & $23 \pm 0.50$ & - & $13 \pm 0.46$ \\
B. cereus & $21 \pm 0.54$ & - & $14 \pm 0.45$ \\
E. coli & - & $22 \pm 0.60$ & $15 \pm 0.44$ \\
P. mirabilis & - & $21 \pm 0.33$ & $11 \pm 0.55$ \\
K. pneumoniae & - & $20 \pm 0.49$ & $0 \pm 0.0$ \\
\hline
\end{tabular}

the antibacterial property of SeNPs stabilized with EWL on B. subtilis (Fig. 7B a-control; b-test) and E. coli (Fig. 7B $C$-control; $d$-test) causing bacterial damage to the peptidoglycan layer. SeNPs stabilized with EWL mainly target the peptidoglycan layer of the bacterial cell membrane where the cytosol content gets leaked out, leading to cell death (Fig. 7B).

\section{Discussion}

In the past years, there seems to be an increased interest in the application of SeNPs as they exhibit antioxidant, anticancer and antimicrobial activities [21, 48]. Therefore, the present study deals with the synthesis of SeNPs using a natural protein, lysozyme obtained from egg white lysozyme. Previous research reveals the photoinduced synthesis of silver nanoparticles stabilized with lysozyme [49]. The nanoparticle synthesis occurred within $2 \mathrm{~h}$, much lesser duration compared to the earlier report where the synthesis process had taken $4 \mathrm{~h}$ using fibroin [47]. In the synthesis process, the aqueous solution of $\mathrm{SeO}_{2}$ was reduced by ascorbic acid. The ascorbic acid solution was used as a precursor to initiating the reaction with $\mathrm{SeO}_{2}$, and the SeNPs were synthesized. In the current study, SeNPs were synthesized with ascorbic acid as reducing agent, and EWL as a stabilizing agent. Previous reports state that employed fibroin protein obtained from silkworm was used as the stabilizing agent for the synthesis of SeNPs [47]. The formation of SeNPs via the reduction of $\mathrm{SeO}_{2}$ was monitored in the UV-visible spectrophotometer. A strong characteristic absorption peak observed at $250 \mathrm{~nm}$ suggests the synthesis of SeNPs (Fig. 1A). Functional groups in the lyophilized SeNPs were examined using FT-IR spectroscopy by scanning in through $4000-450 \mathrm{~cm}^{-1}$. The FT-IR spectrum of SeNPs stabilized with EWL showed bands at 3301 and $2961 \mathrm{~cm}^{-1}$ that were characteristic of hydroxyl groups. The bands at 1308 and $1239 \mathrm{~cm}^{-1}$ correspond to the aromatic primary amine $\mathrm{C}-\mathrm{N}$ stretching vibration, while the bands at 1171 and $1105 \mathrm{~cm}^{-1}$ were characteristic of tertiary and primary $\mathrm{C}-\mathrm{N}$ stretching vibrations. The absorbance band at $1648 \mathrm{~cm}^{-1}$ was characteristic of $C=C$ stretching. The absorbance bands at 668, 743, 897 and
Fig. 7 TEM analyses of antibacterial activities of SeNPs stabilized EWL (a B. subtilis control; b $B$. subtilis tested; $\mathbf{c} E$. coli control; $\mathbf{d}$ E. coli tested)

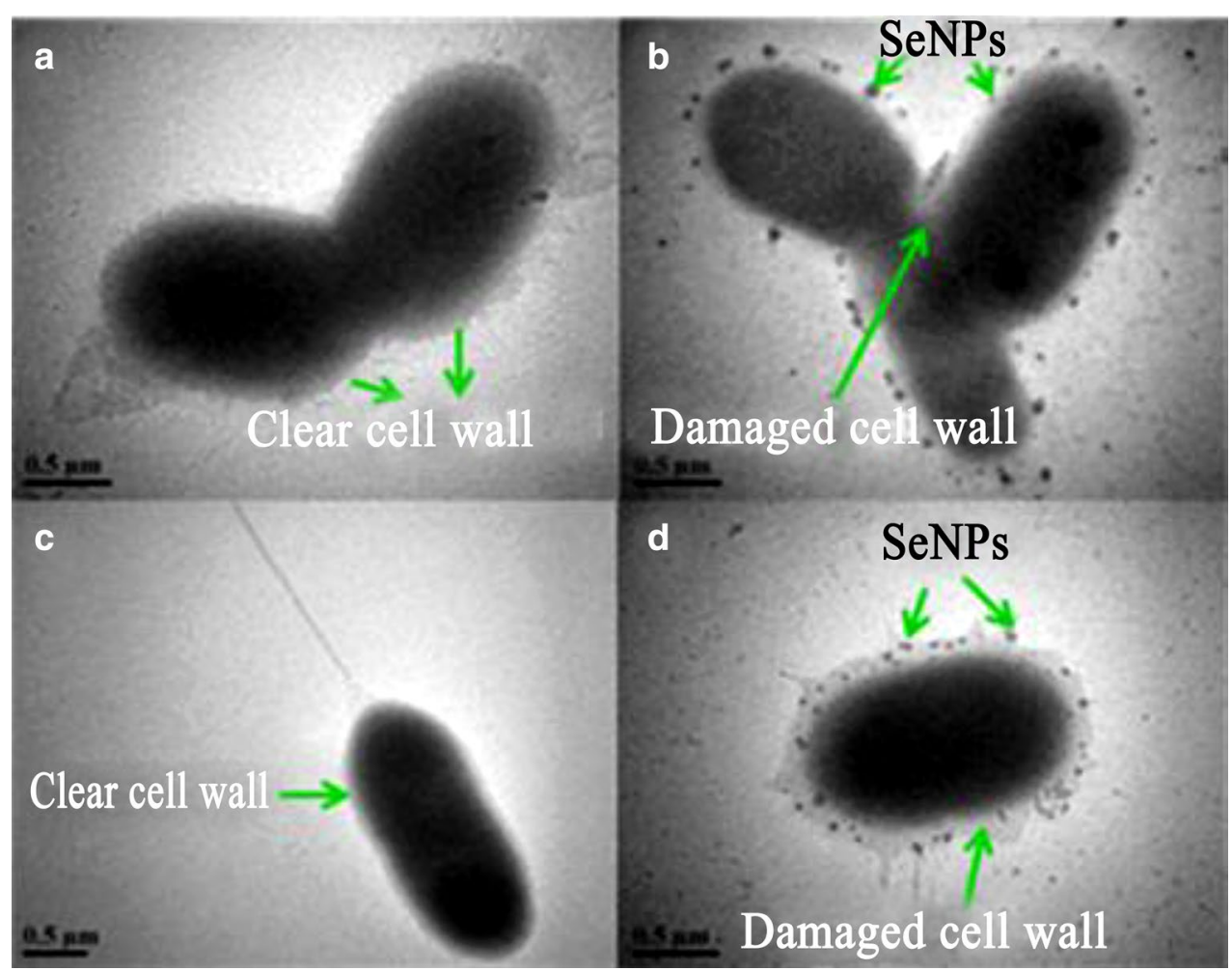


$932 \mathrm{~cm}^{-1}$ were due to aromatic skeleton. The FT-IR peaks of hydroxyl, C-N and aromatic groups were observed and they were similar to the bacterial Comamonas testosteroni S44 synthesized SeNPs stabilized with protein [50]. The peak at $1536 \mathrm{~cm}^{-1}$ was due to aromatic $\mathrm{C}-\mathrm{H}$ stretching vibration. These data suggest that the stabilization of the nanoparticles could be due to the aromatic and hydroxyl group of EWL (Fig. 2; blue line).

$X$-ray diffraction was analysis done to substantiate the crystallite structure of SeNPs and the XRD pattern of SeNPs matches the pattern of SeNPs listed in the ASTM XRD standard card NO.NP-194A, confirming the crystalline structure of SeNPs. A comparison of our XRD spectrum against the standard verified that the synthesized SeNPs formed in this study is nanocrystalline indicated by the peaks at $2 \theta$ corresponding to $2451,725,591,477$ and 281 , respectively, and was compared with the results of Shin (Fig. 3). From the previous study, the X-RD diffraction peaks of green synthesized pure crystalline SeNPs from Withania somnifera was congruent to our SeNPs [51]. The average crystallite size of the synthesized SeNPs was $40-60 \mathrm{~nm}$, following the results obtained in TEM studies (Fig. 4). As shown in Fig. 4, the TEM image of the nanoparticles appeared to be well-dispersed spherical particles, with a diameter of $40-60 \mathrm{~nm}$. Khurana had synthesized SeNPs, which were spherical of size ranging from 20 to $60 \mathrm{~nm}$ [16]. Long-term stability was analyzed to check for aggregation, apart from other parameters like the average diameter and shape, which is a prerequisite for the application of nanomaterial. An excellent stabilization efficacy of EWL on SeNPs formulation was exhibited the stability analysis UV-visible spectrophotometer (Fig. 5). The absorption spectra of SeNPs revealed the changes in the diameter of the nanoparticles, e.g., changes caused due to aggregation of the SeNPs (Fig. 6). Therefore, all stability studies performed in this work were evaluated using UV-visible spectroscopy. The previous study state that the long-term stability of lipid nanoparticles using for biomedical applications [52]. In the systems where ascorbic acid was employed as the reducing agent, the long-term stability was not prone to the changes in concentrations of the gelatin nanoformulation. Nguyen et al. [53] observed the same results, and the synthesis SeNPs was followed at $250 \mathrm{~nm}$ by UV-visible spectrometer. There were not many changes in the UV-visible spectra recorded at varying intervals (Fig. 2a). Dispersions were found to be stable against aggregation [54]. The previous study state that the SeNPs showed antibacterial activity against $P$. aeruginos $(9.25 \mathrm{~mm})$ and $S$. aureus $(10.75 \mathrm{~mm})$ [55]. In the present study, the synthesized SeNPs stabilized with EWL exhibited stronger antibacterial effect against pathogenic bacteria. $10.0 \mu \mathrm{g} \mathrm{ml}^{-1}$ of SeNPs stabilized with EWL was potent enough to inhibit the growth of $B$. subtilis, S. pneumoniae, B. cereus, E. coli, P. mirabilis and K. pneumoniae. The highest zone of inhibition was recorded for $B$. subtilis $(19 \mathrm{~mm})$ followed by S. pneumoniae $(15 \mathrm{~mm})$, B. cereus (14 mm), E. coli $(13 \mathrm{~mm})$ and P. mirabilis $(11 \mathrm{~mm})$. Though SeNPs stabilized with EWL can inhibit both the gram-positive and gram-negative bacteria, more pronounced antibacterial activity was observed with gram-positive bacteria. The SeNPs stabilized with EWL were not effective against $K$. pneumoniae (Fig. 7B; Table 1). Nguyen et al. [53] also reported similar study; $10 \mu \mathrm{g}$ concentration of SeNPs inhibits the foodborne pathogens. The reason why SeNPs stabilized with EWL failed to curb the growth of $K$. pneumoniae remains to be investigated. TEM image reveals the antibacterial potential of SeNPs stabilized with EWL on B. subtilis and E. coli, causing bacterial damage to the peptidoglycan layer. SeNPs stabilized with EWL mainly target the peptidoglycan layer of the bacterial cell membrane, causing the leakage of cytosol content resulting in cell death, as observed by Narayanan (Fig. 7B).

\section{Conclusion}

This study deals with the synthesis of SeNPs using EWL and ascorbic acid for the generation of metal nanoparticles. The solvents and reducing agents determine the physical and morphological characteristics of SeNPs. The size, conformation and morphological characteristics of the newly synthesized nanoparticles were studied by UV-Vis, FT-IR, XRD and TEM analyses. The EWL stability dispersions of SeNPs were observed to exhibit prolonged stability minimum 12 months, which was confirmed by the TEM image. The antibacterial efficacies of the reported SeNPs stabilized with EWL have been proved to be promising against different pathogenic bacteria. Hence, further studies are to be conducted in this research area to be employed in the pharmaceutical industry, and this would be a cost-effective alternative to other approaches.

Acknowledgements The authors thank the University Grant Commission-Basic Science Research (UGC-BSR) Science Meritorious Fellowship (GCCO/A2/UGC/PT/CASB/MER FELLOW/2009/1484), New Delhi, India, for financially supporting this work.

\section{Compliance with ethical standards}

Conflict of interest The authors report no conflict of interest. The authors are the only responsible person for the content and drafting of this article.

\section{References}

1. Dudefoi W, Villares A, Peyron S, Moreau C, Ropers MH, Gontard N, Cathala B (2018) Nanoscience and nanotechnologies for biobased materials, packaging and food applications: new opportunities and concerns. Innov Food Sci Emerg Technol. https://doi.org/10.1016/j.ifset.2017.09.007 
2. Alananbeh KM, Al-Qudah Z, El-Adly A, Al Refaee WJ (2017) Impact of silver nanoparticles on bacteria isolated from raw and treated wastewater in Madinah, KSA. Arab J Sci Eng. https://doi. org/10.1007/s13369-016-2133-3

3. Alananbeh KM, Al-REFAEE WJ, Qodah ZA (2017) Antifungal effect of silver nanoparticles on selected fungi isolated from raw and waste water. Indian J Pharm Sci. https://doi.org/10.4172/pharm aceutical-sciences.1000263

4. Kim BH, Lee N, Kim H et al (2011) Large-scale synthesis of uniform and extremely small-sized iron oxide nanoparticles for high-resolution T 1 magnetic resonance imaging contrast agents. J Am Chem Soc. https://doi.org/10.1021/ja203340u

5. Moon JW, Rawn CJ, Rondinone AJ, Love LJ, Roh Y, Everett SM, Lauf RJ, Phelps TJ (2010) Large-scale production of magnetic nanoparticles using bacterial fermentation. J Ind Microbiol Biotechnol. https://doi.org/10.1007/s10295-010-0749-y

6. Journet C, Picher M, Jourdain V (2012) Carbon nanotube synthesis: from large-scale production to atom-by-atom growth. Nanotechnology. https://doi.org/10.1088/0957-4484/23/14/142001

7. Velásquez EA, Altbir D, Mazo-Zuluaga J, Duque LF, Mejía-López $J$ (2013) Searching for the nanoscopic-macroscopic boundary. J Magn Magn Mater. https://doi.org/10.1016/j.jmmm.2013.08.029

8. Li Z, Barnes JC, Bosoy A, Stoddart JF, Zink JI (2012) Mesoporous silica nanoparticles in biomedical applications. Chem Soc Rev. https://doi.org/10.1039/c1cs15246g

9. Subbiah R, Veerapandian M, Yun KS (2011) Nanoparticles: functionalization and multifunctional applications in biomedical sciences. Curr Med Chem. https://doi.org/10.2174/0929867107 94183024

10. Guo D, Xie G, Luo J (2014) Mechanical properties of nanoparticles: basics and applications. J Phys D Appl Phys. https://doi. org/10.1088/0022-3727/47/1/013001

11. Li ZF, Zhang H, Liu Q, Sun L, Stanciu L, Xie J (2013) Fabrication of high-surface-area graphene/polyaniline nanocomposites and their application in supercapacitors. ACS Appl Mater Interfaces. https://doi.org/10.1021/am4001634

12. Rai M, Ingle A (2012) Role of nanotechnology in agriculture with special reference to management of insect pests. Appl Microbiol Biotechnol. https://doi.org/10.1007/s00253-012-3969-4

13. Agrawal S, Rathore P (2014) Nanotechnology pros and cons to agriculture: a review. Int J Curr Microbiol Appl Sci. https://doi. org/10.13140/2.1.1648.1926

14. Mousavi S, Rezaei M (2011) Nanotechnology in agriculture and food production. J Appl Environ Biol Sci. https://doi. org/10.4172/2157-7439.1000123

15. Martirosyan A, Schneider YJ (2014) Engineered nanomaterials in food: implications for food safety and consumer health. Int J Environ Res Public Health. https://doi.org/10.3390/ijerph1106 05720

16. Khurana A, Tekula S, Saifi MA, Venkatesh P, Godugu C (2019) Therapeutic applications of selenium nanoparticles. Biomed Pharmacother. https://doi.org/10.1016/j.biopha.2018.12.146

17. Hosnedlova B, Kepinska M, Skalickova S et al (2018) Nano-selenium and its nanomedicine applications: a critical review. Int J Nanomed. https://doi.org/10.2147/IJN.S157541

18. Haug A, Graham RD, Christophersen OA, Lyons GH (2007) How to use the world's scarce selenium resources efficiently to increase the selenium concentration in food. Microb Ecol Health Dis. https://doi.org/10.1080/08910600701698986

19. Boylan LM, Spallholz JE (2005) Selenium. In: Wolinsky I, Driskell J (eds) Sports nutrition: vitamins and trace elements, Chapter 19. CRC Press, Inc., Boca Raton, FL, pp 275-286

20. Jampilek J, Kos J, Kralova K (2019) Potential of nanomaterial applications in dietary supplements and foods for special medical purposes. Nanomaterials. https://doi.org/10.3390/nano 9 020296
21. Gunti L, Dass RS, Kalagatur NK (2019) Phytofabrication of selenium nanoparticles from emblica officinalis fruit extract and exploring its biopotential applications: antioxidant, antimicrobial, and biocompatibility. Front Microbiol. https://doi. org/10.3389/fmicb.2019.00931

22. Fardsadegh $B$, Vaghari $H$, Mohammad-Jafari $R$, Najian $Y$, Jafarizadeh-Malmiri H (2019) Biosynthesis, characterization and antimicrobial activities assessment of fabricated selenium nanoparticles using Pelargonium zonale leaf extract. Green Process Synth. https://doi.org/10.1515/gps-2018-0060

23. Kumar A, Bera S, Singh M, Mondal D (2018) Agrobacteriumassisted selenium nanoparticles: molecular aspect of antifungal activity. Adv Nat Sci Nanosci Nanotechnol. https://doi. org/10.1088/2043-6254/aa9f4a

24. Joshi SM, De Britto S, Jogaiah S, Ito S (2019) Mycogenic selenium nanoparticles as potential new generation broad spectrum antifungal molecules. Biomolecules. https://doi. org/10.3390/biom9090419

25. Wang Q, Mejía Jaramillo A, Pavon JJ, Webster TJ (2016) Red selenium nanoparticles and gray selenium nanorods as antibacterial coatings for PEEK medical devices. J Biomed Mater Res Part B Appl Biomater. https://doi.org/10.1002/jbm.b.33479

26. Rodríguez-Valencia $C$, Lopez-Álvarez $M$, Cochón-Cores $B$, Pereiro I, Serra J, González P (2013) Novel selenium-doped hydroxyapatite coatings for biomedical applications. J Biomed Mater Res, Part A. https://doi.org/10.1002/jbm.a.34387

27. Vera P, Echegoyen Y, Canellas E, Nerín C, Palomo M, Madrid Y, Cámara C (2016) Nano selenium as antioxidant agent in a multilayer food packaging material. Anal Bioanal Chem. https ://doi.org/10.1007/s00216-016-9780-9

28. Vera P, Canellas E, Nerín C (2018) New antioxidant multilayer packaging with nanoselenium to enhance the shelflife of market food products. Nanomaterials. https://doi. org/10.3390/nano8100837

29. Mates I, Antoniac I, Laslo V, Vicas S, Brocks M, Fritea L, Milea C, Mohan A, Cavalu S (2019) Selenium nanoparticles: production, characterization and possible applications in biomedicine and food science. UPB Sci Bull Ser B Chem Mater Sci 81:205-216

30. Khiralla GM, El-Deeb BA (2015) Antimicrobial and antibiofilm effects of selenium nanoparticles on some foodborne pathogens. LWT Food Sci Technol. https://doi.org/10.1016/j. Iwt.2015.03.086

31. Khan I, Saeed K, Khan I (2017) Nanoparticles: properties, applications and toxicities. Arab J Chem. https://doi.org/10.1016/j. arabjc.2017.05.011

32. Sarangan A (2016) Nanofabrication. Fundam Appl Nanophotonics. https://doi.org/10.1016/B978-1-78242-464-2.00005-1

33. Niemeyer CM (2010) Semisynthetic DNA-protein conjugates for biosensing and nanofabrication. Angew Chem Int Ed. https ://doi.org/10.1002/anie.200904930

34. Li H, Carter JD, LaBean TH (2009) Nanofabrication by DNA self-assembly. Mater Today. https://doi.org/10.1016/S1369 -7021(09)70157-9

35. Sano Kl, Sasaki H, Shiba K (2006) Utilization of the pleiotropy of a peptidic aptamer to fabricate heterogeneous nanodotcontaining multilayer nanostructures. J Am Chem Soc. https ://doi.org/10.1021/ja057262r

36. Castillo-León J (2014) Fabrication of nanostructures using selfassembled peptides as templates: the diphenylalanine case. Micro Nanofabrication Using Self Assem Biol Nanostruct. https ://doi.org/10.1016/B978-0-323-29642-7.00002-3

37. Fernandez-Fernandez A, Manchanda R, McGoron AJ (2011) Theranostic applications of nanomaterials in cancer: drug delivery, image-guided therapy, and multifunctional platforms. Appl Biochem Biotechnol. https://doi.org/10.1007/ s12010-011-9383-z 
38. Wadhwani SA, Shedbalkar UU, Singh R, Chopade BA (2016) Biogenic selenium nanoparticles: current status and future prospects. Appl Microbiol Biotechnol. https://doi.org/10.1007/s0025 3-016-7300-7

39. Nasrolahi Shirazi A, Tiwari RK, Oh D, Sullivan B, Kumar A, Beni YA, Parang K (2014) Cyclic peptide-selenium nanoparticles as drug transporters. Mol Pharm. https://doi.org/10.1021/mp500364a

40. Weingart J, Vabbilisetty P, Sun XL (2013) Membrane mimetic surface functionalization of nanoparticles: methods and applications. Adv Colloid Interface Sci. https://doi.org/10.1016/j. cis.2013.04.003

41. Li T, Smet M, Dehaen W, Xu H (2016) Selenium-platinum coordination dendrimers with controlled anti-cancer activity. ACS Appl Mater Interfaces. https://doi.org/10.1021/acsami.5b07877

42. Prasanth S, Sudarsanakumar C (2017) Elucidating the interaction of L-cysteine-capped selenium nanoparticles and human serum albumin: spectroscopic and thermodynamic analysis. New J Chem. https://doi.org/10.1039/c7nj00477j

43. Epaud R, Delestrain C, Weaver TE, Akinbi HT (2019) Bacterial killing is enhanced by exogenous administration of lysozyme in the lungs. Respir Med Res. https://doi.org/10.1016/j.resme r.2019.07.005

44. Lee-Huang S, Huang PL, Sun Y, Huang PL, Kung HF, Blithe DL, Chen HC (1999) Lysozyme and RNases as anti-HIV components in $\beta$-core preparations of human chorionic gonadotropin. Proc Natl Acad Sci USA. https://doi.org/10.1073/pnas.96.6.2678

45. Ashraf S, Chatha MA, Ejaz W, Janjua HA, Hussain I (2014) Lysozyme-coated silver nanoparticles for differentiating bacterial strains on the basis of antibacterial activity. Nanoscale Res Lett. https://doi.org/10.1186/1556-276X-9-565

46. Ragland SA, Criss AK (2017) From bacterial killing to immune modulation: recent insights into the functions of lysozyme. PLoS Pathog. https://doi.org/10.1371/journal.ppat.1006512

47. Xia YY (2007) Synthesis of selenium nanoparticles in the presence of silk fibroin. Mater Lett 61:4321-4324

48. Shubharani R, Mahesh M, Yogananda Murthy V (2019) Biosynthesis and characterization, antioxidant and antimicrobial activities of selenium nanoparticles from ethanol extract of bee propolis.
J Nanomed Nanotechnol 1:1. https://doi.org/10.4172/21577439.1000522

49. Rey V, Gramajo Feijoo ME, Giménez RE, Tuttolomondo ME, Morán Vieyra FE, Sosa Morales MC, Borsarelli CD (2018) Kinetics and growth mechanism of the photoinduced synthesis of silver nanoparticles stabilized with lysozyme. Colloids Surf B Biointerfaces. https://doi.org/10.1016/j.colsurfb.2018.08.015

50. Di Xu, Yang L, Wang Y, Wang G, Rensing C, Zheng S (2018) Proteins enriched in charged amino acids control the formation and stabilization of selenium nanoparticles in Comamonas testosteroni S44. Sci Rep. https://doi.org/10.1038/s41598-018-23295 $-5$

51. Alagesan V, Venugopal S (2019) Green synthesis of selenium nanoparticle using leaves extract of Withania somnifera and its biological applications and photocatalytic activities. Bionanoscience. https://doi.org/10.1007/s12668-018-0566-8

52. Lball R, Bajaj P, Whitehead KA (2017) Achieving long-term stability of lipid nanoparticles: examining the effect of $\mathrm{pH}$, temperature, and lyophilization. Int J Nanomed. https://doi.org/10.2147/ IJN.S123062

53. Nguyen THD, Vardhanabhuti B, Lin M, Mustapha A (2017) Antibacterial properties of selenium nanoparticles and their toxicity to Caco-2 cells. Food Control. https://doi.org/10.1016/j.foodc ont.2017.01.018

54. Sivera M, Kvitek L, Soukupova J, Panacek A (2014) Silver nanoparticles modified by gelatin with extraordinary $\mathrm{pH}$ stability and long-term antibacterial activity. PLoS ONE 9:e103675

55. Boroumand S, Safari M, Shaabani E, Shirzad M, Faridi-Majidi R (2019) Selenium nanoparticles: synthesis, characterization and study of their cytotoxicity, antioxidant and antibacterial activity. Mater Res Express 6:8. https://doi.org/10.1088/2053-1591/ ab2558

Publisher's Note Springer Nature remains neutral with regard to jurisdictional claims in published maps and institutional affiliations. 